\title{
School Absenteeism Among Children
}

\author{
MKC NAIR \\ Director, Child Development Centre, Medical College Campus, Thiruvananthapuram 695 011, Kerala, India. \\ nairmkc@rediffmail.com
}

$\mathrm{E}$ ducational success of children is close to the heart of most educated parents in India. Economic success and social upliftment in life was always closely related to jobs, whose prerequisite was only academic achievement. But in the recent times, with the advent of the information technology industry, there is increasing emphasis on skill development and attitude - ability for teamwork, even more than knowledge per se. In spite of massive governmental impetus, the education scene in India is volatile and new initiatives are being introduced both for secondary education and higher education. While the "need" for inclusive primary education for all is the priority of the government, the private sector is increasingly catering to the "want" of parents for "sophisticated" exclusive schools and colleges for their children.

Parliament has passed the historic "Right of Children to Free and Compulsory Education Bill, 2008", which envisages providing free and compulsory education to 6-14 year old children. In the list of Education For All (EFA) Development Index, among 125 countries, India ranks 99th, even though there have been reductions in the number of out-of-school children since 2004. Most likely we need better understanding of the issues involved, starting with the burden of problem, the causative and associate factors, interventional strategies and cost effectiveness of school based programs at national level.

School absenteeism may include specific lesson absence, post-registration absence, parentally condoned absence, psychological absence, school refusal and school phobia. Malcolm, et al.(1) use three different terms to describe pupils' non- attendance; $(i)$ 'Truancy' defined as 'absences which pupils themselves indicated would be unacceptable to teachers, (ii) 'Unacceptable absences' defined as 'absences, which were unacceptable to teachers and local education authorities (LEAs) but not recognised as such by pupils' and (iii) 'Parentally condoned absences' resulting from parents or caretakers keeping pupils away from school. Also teacher absenteeism remains a serious problem in developing countries like India. Gender disparity in education is also prevalent in India(2).

Main causes of truancy and disruptive behaviour among children over 7 years of age, in rank order were; $(i)$ the influence of friends and peers, (ii) relations with teachers, often those lacking in respect for pupils, (iii) the content and delivery of the curriculum, (iv) family aspects - parents' attitudes, domestic problems, ( $v$ ) bullying and (vi) the classroom context, for example lack of control or pupils' learning difficulties(3). Absenteeism from school is a serious public health issue for mental health professionals, physicians, and educators. The prevalence of unexcused absences from school exceeds that of major childhood behavior disorders and is a key risk factor for violence, injury, substance use, psychiatric disorders, and economic deprivation(4).

Atkinson, et al.(5) provided a useful classification of initiatives aimed at improving attendance, including; (i) Having appropriate service-level agreements; ( $i i)$ formulating preventive strategies, involving all pupils within a school or year group or all teachers within a school; (iii) Having clear initial and first-day responses for absence, targeting particular pupils, days and 
lessons; (iv) implementing appropriate early intervention schemes; $(v)$ targeting pupils whose attendance falls below a certain level; (vi) identifying specific attendance problems in schools; (vii) having good strategies to deal with disaffected behaviour; and (viii) fostering appropriate interdisciplinary and multidisciplinary links.

A review of available research on micronutrient supplementation found that iron therapy improve cognitive performance, whereas zinc and iodine therapy did not, and there was no evidence that population, wide vitamin and mineral supplementation leads to improved academic performance(6). Studies (RCTs) in both Kenya and India have found a significant impact due to deworming on school attendance. Absenteeism fell by one quarter in the Kenyan study(7) and one fifth in India(8). A study done in Delhi's resettlement colonies in 200 schools showed that de-worming programs can be a cost-effective health intervention in improving student participation in India(9). The Campbell review of 18 studies including 7 RCTs on impact of school feeding, indicated that it increase attendance, particularly in rural low-income schools in developing countries, and improve cognitive performance at least in the short term(10).

Longitudinal studies indicate that if left unaddressed, school refusal behaviour can lead to serious short-term problems such as distress, academic decline, alienation from peers, family conflict, and financial and legal consequences. Common long-term problems include school dropout, delinquent behaviours, economic deprivation, social isolation, marital problems, and difficulty maintaining employment. We need to remember that school absenteeism may be a cry for help and only a symptom of deep-rooted psychological or adjustment problems. Approximately 52\% of adolescents with school refusal behaviour meet criteria for an anxiety, depressive, conduct-personality, or other psychiatric disorder later in life(11). The pediatrician, does have the right and responsibility to see the child smoothly through the school years to a professional setting - skilled or unskilled, preparing them to set up a family of their own.
Funding: None.

Competing interests: None stated.

\section{REFERENCES}

1. Malcolm H, Wilson V, Davidson J, Kirk S. Absence from School: A Study of its Causes and Effects in Seven LEAs. Nottingham: DFES Report 424; 2003.

2. Pandey V. Teacher absenteeism ails Indian education. Mumbai. Daily News and Analysis; Thursday, Oct 26, 2006. http://www.dnaindia.com/ india/report teacher-absenteeism-ails-indianeducation_1060396. Accessed 16 August, 2010.

3. Kinder K, Wakefield A, Wilkin A. Talking Back: Pupil Views on Disaffection. Slough: NFER; 1996.

4. Kearney CA. School absenteeism and school refusal behavior in youth - A contemporary review. Clin Psychol Rev 2008; 28: 451-471.

5. Atkinson M, Halsey K, Wilkin A, Kinder K. Raising Attendance. Slough: NFER; 2000.

6. Taras H. Nutrition and student performance in school. J School Health 2005; 75: 199-213.

7. Miguel E, Kremer M. Worms: identifying impacts on education and health in the presence of treatment externalities. Econometrica 2004; 72: 159-217.

8. Bobonis G, Miguel E, Sharma C. Iron Deficiency Anemia and School Participation, Poverty Action Lab Paper No.7. Cambridge, MA, J-PAL; 2004.

9. Bossuroy T, Delavallade C. Deworming improves school attendance. http://southasia.oneworld.net/ todaysheadlines/deworming-improves-schoolattendance-says-report. Accessed 18 November, 2008.

10. Kristjansson EA, Robinson V, Petticrew M, MacDonald B, Krasevec J, Janzen L, et al. School Feeding for Improving the Physical and Psychosocial Health of Disadvantaged Elementary School Children. Copenhagen: Campbell Review, SFI Campbell; 2007.

11. Kearney CA. Dealing with school refusal behaviour - A primer for family physicians. J Fam Pract. From: http://www.jfponline.com/Pages.asp?AID= 4322\&UID. Accessed 15 August, 2010. 